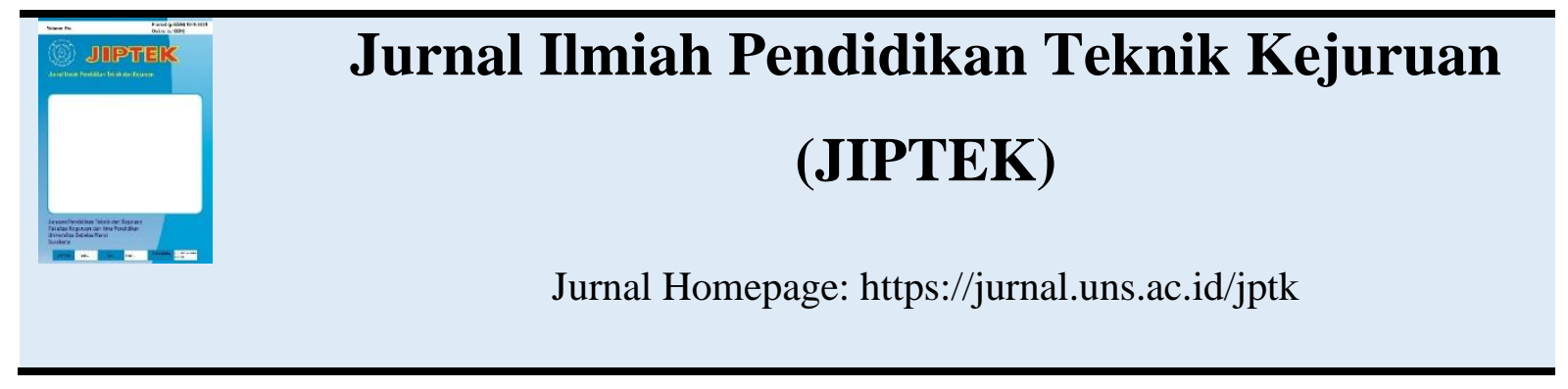

\title{
PELATIHAN PENYUSUNAN MODUL PEMBELAJARAN MATA PELAJARAN PRODUKTIF BERBASIS KKNI DAN KEBUTUHAN INDUSTRI GURU-GURU SMK KOTA SURAKARTAPROGRAM KEAHLIAN TEKNIK OTOMOTIF
}

\author{
Herman Saputro ${ }^{1}$, Ranto $^{2}$, Husin Bugis ${ }^{3}$, Muchamad Yusuf Adi Rahmawan ${ }^{4}$ \\ 1,2,3,4 Pendidikan Teknik Mesin, Fakultas Keguruan dan Ilmu Pendidikan, Universitas \\ Sebelas Maret Surakarta \\ E-mail: hermansaputro@staff.uns.ac.id
}

\begin{abstract}
ABSTRAK
Sekolah Menengah Kejuruan (SMK) bertugas menyiapkan siswa untuk siap bekerja di industri. Tugas tersebut dapat tercapai jika proses pembelajarannya dilaksankan berbasis kompetensi di industri dan Kerangka Kualifikasi Nasional Indonesia (KKNI) level 2. Salah satu cara agar pembelajaran di VHS relevan dengan kompetensi di industri yaitu dengan pengembangan materi pembelajaran bersama industri. Materi pembelajaran dapat dikemas dalam bentuk modul pembelajaran. Namun, saat ini modul pembelajaran yang relevan dengan kompetensi di industry tidak banyak di VHS. Ketiadaan modul pembelajaran tersebut dapat diatasi dengan cara para guru diberikan pelatihan penyusunan modul. Pelatihan penyusunan modul pembelajaran dilakukan berdasarkan KKNI dan kompetensi industry. Indikator pencapaian kompetensi di kurikulum diperbaiki dan disempurnakan rumusannya menyesuaikan perkembangan teknologi baru di industri otomotif. Pelatihan diberikan kepada guru-guru produktif teknik kendaraan ringan otomotif dengan jumlah peserta18 orang. Produk dari kegiatan pengabdian ini adalah terlatihnya guru-guru SMK pengampu mata pelajaran produktif di Kota Surakarta dalam menyusun dan mengembangkan modul pembelajaran mata pelajaran produktif teknik kendaraan ringan otomotif yang selaras dengan KKNI level 2 dan kompetensi teknisi otomotif di industri. Dampak yang diharapkan dari kegiatan ini adalah tersusunnya modul pembelajaran oleh para guru, yang selanjutnya dapat digunakan dalam proses pembelajarannya. Dengan demikian proses pembelajaran dapat meningkat kualitasnya, sehingga kompetensi siswa akan meningkat.
\end{abstract}

Kata kunci: Modul pembelajaran otomotif, KKNI Level 2

\begin{abstract}
Vocational High School (VHS) is tasked with preparing students to work in the industry. This task can be achieved if the learning process is carried out based on industry competency and level 2 of the Indonesian National Qualification Framework (KKNI). One way to make learning in VHS relevant to the industry's competencies is by developing learning materials with the industry. Learning materials can be packaged in the form of learning modules. However, there are not many learning modules that are relevant to competencies in the industry in VHS. The absence of this learning module can be overcome by giving teachers training in module preparation. Training for the preparation of learning modules is carried out based on KKNI and industrial competencies. The curriculum's competency achievement indicators are improved, and the formulation is refined
\end{abstract}


according to new technological developments in the automotive industry. The training was given to productive automotive light vehicle engineering teachers with a total of 18 participants. The product of this service activity is the training of SMK teachers who teach productive subjects in the City of Surakarta in compiling and developing learning modules for productive subjects in automotive light vehicle engineering that are in line with KKNI level 2 and the competence of automotive technicians in the industry. The expected impact of this activity is the teachers' arrangement of learning modules, which can then be used in the learning process. Thus the learning process can improve its quality so that that student competence will increase.

Keywords: Learning module, KKNI level 2

\section{PENDAHULUAN}

Prosser dan Ougley, 1950 mengusulkan konsep ideal untuk pendidikan kejuruan melalui Enam Belas Teorema Prosser tentang Pendidikan Kejuruan. Salah satu dari Enam Belas Teorema Prosser yaitu pendidikan vokasi akan efisien apabila lingkungan tempat peserta didik dilatih merupakan replika dari lingkungan tempat mereka bekerja nantinya. Hal ini dapat diartikan bahwa kompetensi dalam kurikulum SMK harus mengikuti industri. Kompetensi lulusan SMK menjadi kunci penerimaan di pasar kerja. Beberapa penelitian mengenai kompetensi di VHS Indonesia telah dilakukan, seperti Saputro et al. 2018, yang meneliti pendidikan berbasis produksi di SMK. Estriyanto et al., 2017 yang meneliti kompetensi guru di SMK, Indonesia. Kesesuaian kompetensi dalam industri menjadi perhatian penting yang harus dilakukan Kapasir et al., 2019. Namun tidak semua industri memperhatikan dunia pendidikan, seperti yang dilaporkan dalam penelitian Wibowo dan Munadi, 2019.

Perkembangan industri berjalan sangat cepat, demikian juga industri otomotif. Teknologi mesin otomotif yang dulu konvensional dan sangat sederhana, sekarang semuanya dikontrol secara elektronik sehingga mesin otomotif bekerja lebih efisien dan menghasilkan tenaga lebih besar serta meningkat tingkat keselamatannya. Akibat dari perkembangan teknologi otomotif tersebut mesin menjadi lebih rumit dan komplek. Dengan demikian perawatan dan perbaikan mesin kendaraan memerlukan SDM yang kompeten dan sesuai perkembangan teknologi otomotif terkini, SMK harus dapat memenuhinya. Agar pembelajaran di SMK bisa menghasilkan lulusan yang memiliki kompetensi industri otomotif terkini, maka diperlukan sarana prasarana pembelajaran yang sesuai kebutuhan industri otomotif terkini serta guru yang kompeten. Saat ini SMK menggunakan Kurikulum 2013 yang disempurnakan pada tahun 2018. Jika sarana prasarana pembelajaran dipenuhi dan proses pembelajaran dilaksanakan dengan baik, maka SMK dapat menghasilkan lulusan yang kompeten dan relevan dengan industri. Salah satu sarana pembelajaran penting adalah bahan ajar atau modul pembelajaran. Modul pembelajaran yang baik tentunya yang sesuai dengan KKNI dan kompetensi industri. Prodi PTM sebagai penyedia dan pengembang guru SMK teknik otomotif 
sudah seharusnyalah peduli kepada SMK, terutama dalam pendampingan penyelenggaraan pembelajaran, termasuk dalam hal pendampingan penyusunan modul pembelajaran yang sesuai dengan KKNI dan kompetensi teknisi otomotif terkini di industri.

Berdasarkan observasi ketika bertugas sebagai dosen PDS (Penugasan Dosen di Sekolah) dan laporan para mahasiswa yang menyelenggarakan PPL di sekolah, terdapat beberapa permasalahan yang berkaitan dengan pelaksanaan pembelajaran yang perlu diatasi, salah satunya adalah ketersediaan modul pembelajaran yang baik dan operasional. Modul pembelajaran atau bahan ajar yang baik adalah yang sesuai atau relevan dengan kompetensi yang dibutuhkan industri terkini serta sesuai dengan level kompetensi lulusan SMK, yakni KKNI level 2. Selain itu modul juga menarik dan mudah dipelajari. Bahan ajar yang ada di SMK berupa buku manual dari merk mobil tertentu yang jumlahnya hanya satu atau dua buah, sehingga sulit digunakan sebagai bahan ajar yang harus dibagikan ke siswa. Bahan ajar lain yang ada juga format dan susunannya kurang menarik, bahkan sering dijumpai proses pembelajaran tanpa bahan ajar di tangan siswa. Untuk dapat meningkatkan kualitas pembelajaran teori maupun praktek perawatan dan perbaikan kendaraan ringan agar menghasilkan lulusan yang kompeten dan sesuai dengan kebutuhan industri otomotif, maka sangat diperlukan kemampuan guru untuk menyusun atau mengembangkan sendiri modul pembelajaran yang sesuai denganKKNI level 2 dan kompetensi teknisi otomotif di industri. Berdasarkan kondisi tersebut, maka program pengabdian kepada masyarakat dengan judul "Pelatihan Penyusunan Modul Pembelajaran Mata Pelajaran Produktif berbasis KKNI dan Kebutuhan Industri Guru-guru SMK Kota Surakarta Program Keahlian Teknik Otomotif." ini sangat diperlukan dan penting untuk dilaksanakan.

\section{URAIAN KEGIATAN DAN METODE PELAKSANAAN PENGABDIAN}

\section{Bentuk Kegiatan}

Kegiatan pengabdian kepada masyarakat Pelatihan penyusunan modul pembelajaran berbasis KKNI dan kompetensi industri. Pelatihan dilakukan secara luring pada pada Tahap 1 peserta sebanyak 10 Guru dari SMK Warga Surakarta. Pada Tahap 2 dilakukan di SMK Pancasila Surakarta. modul pembelajaran berbasis KKNI yang disusun oleh guru diimplemantasikan di sekolah masing-masing, untuk selanjutnya dianalisis untuk dilakukan penyempurnaan modul. Hasil pengabdian ini dapat digunakan untuk mengembangkan pembelajaran yang salah satu fokusnya adalah mengatasi kesulitan guru untuk menyusun atau mengembangkan sendiri modul pembelajaran yang sesuai dengan KKNI level 2 dan kompetensi teknisi otomotif di industri

\section{Waktu, Lokasi, dan Peserta}

Pengabdian ini direncanakan akan dilaksanakan 2 tahap, Tahap 1 telah dilakukan pada 5 Agustus 2020 di SMK 
Warga Surakarta dan Tahap 2 dilakukan pada 11 September 2020 di SMK Pancasila Surakarta. Peserta dari kegiatan ini adalah guru-guru di SMK Warga Surakarta dan SMK Pancasila Surakarta.

\section{Data dan Sumber Data}

Pengabdian ini akan mengambil data pemahaman guru SMK Warga dan SMK Pancasila dalam mengembangkan modul pembelajaran berbasis KKNI dan kompetensi industri.

\section{HASIL DAN PEMBAHASAN}

Pada pelatihan tahap pertama dilakukan pada tanggal 5 Agustus 2020 di SMK Warga Surakarta secara luring. Pada tahap 1 diikuti oleh 10 orang guru, pembatasan jumlah peserta ini dikarenakan adanya pandemic covid 19 .

Pelatihan tahap 1:

1. Bagian 1: Pengantar tentang KKNI dan kompetensi industri

Standar Kompetensi Kerja Nasional Indonesia (SKKNI) adalah uraian kemampuan yang mencakup pengetahuan, keterampilan dan sikap kerja minimal yang harus dimiliki seseorang untuk menduduki jabatan tertentu yang berlaku secara Nasional. Standar tersebut adalah acuan yang dibuat oleh industri yang digunakan untuk menetapkan tingkat kemampuan yang efektif dalam perawatan dan perbaikan di bengkel otomotif. Standar tersebut merupakan kerangka kerja yang sesuai dengan kebutuhan semua pihak yang terkait, pemerintah, industri, lembaga pelatihan dan peserta pelatihan. Agar lebih berdayaguna dan sesuai adalah penting bahwa pelatihan dan penilaian yang berhubungan dengan standar tersebut dilaksanakan dalam suatu cara yang dapat memenuhi kebutuhan khusus dari industri dan peserta pelatihan. Dengan cara ini pelatihan yang sebenarnya dibutuhkan oleh industri akan tercapai.

Kompetensi kunci yaitu Keterampilan umum yang diperlukan agar kriteria unjuk kerja tercapai pada tingkatan kinerja yang dipersyaratkan untuk peran / fungsi pada suatu pekerjaan. Kompetensi kunci meliputi:

a. Mengumpulkan, mengorganisir dan menganalisa informasi.

b. Mengkomunikasikan ide-ide dan informasi.

c. Merencanakan dan mengorganisir aktifitas-aktifitas.

d. Bekerja dengan orang lain dan kelompok.

e. Menggunakan ide-ide dan teknik matematika.

f. Memecahkan masalah.

g. Menggunakan teknologi.

Kompetensi kunci dibagi dalam tiga tingkatan yaitu:

- Tingkat 1 harus mampu:

a melaksanakan proses yang telah ditentukan.

b. menilai mutu berdasarkan kriteria yang telah ditentukan.

- Tingkat 2 harus mampu:

a. mengelola proses. 

b. menentukan kriteria untuk mengevaluasi proses.

- Tingkat 3 harus mampu:

a menentukan prinsip-prinsip dan proses.
b. mengevaluasi dan mengubah bentuk proses.
c. menentukan kriteria untuk pengevaluasian proses.

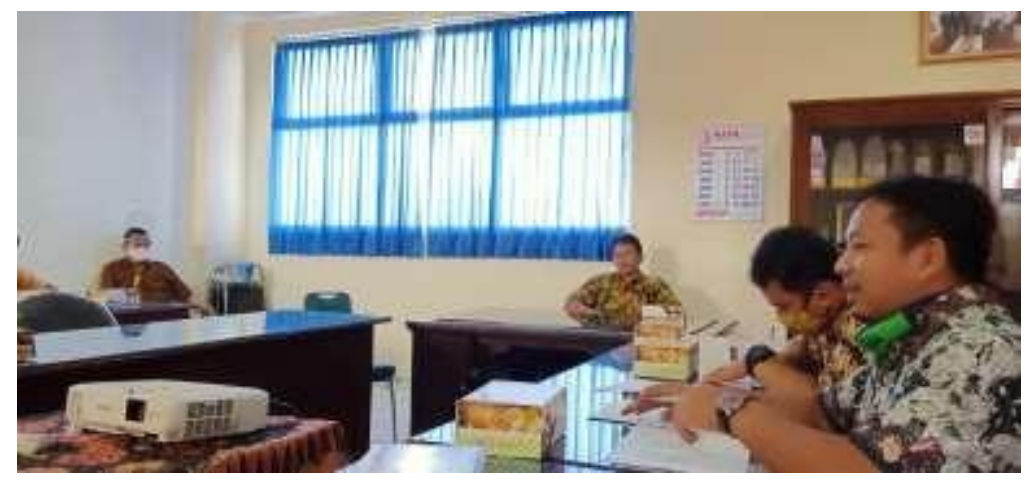

a.

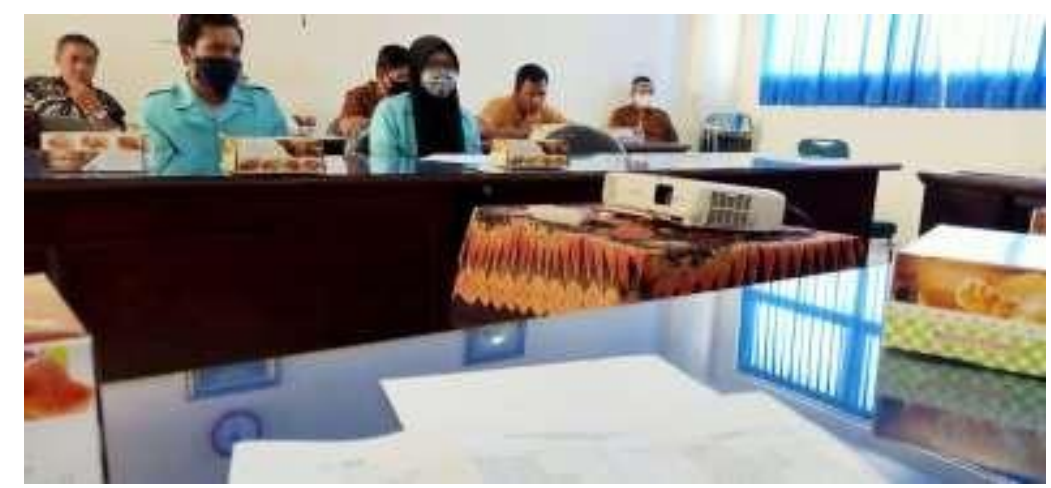

b.

Gambar 1 (a) Pengantar tentang KKNI; (b) Pengantar kompetensi industri

\section{Bagian 2: Penyusunan modul}

\section{Analisis Materi}

Guru memilih salah satu materi yang akan dibuat modul, contohnya modul kelistrikan otomotif berbasis KKNI. Materi ini terbagi menjadi 2 yaitu Memahami nama-simbol kelistrikan dan membaca wiring diagram. Pengambilan materi tersebut dikarenakan di kelas XII memiliki waktu KBM yang pendek sehingga langsung diberikan materi pada kompetensi terakhir yaitu Memahami nama-simbol kelistrikan dan membaca wiring diagram. Selain itu, materi awal tentang mesin kelistrikan otomotif telah diberikan pada saat kelas XI sehingga cukup mengulang sedikit untuk mengingatkan siswa tetapi materi inti yang diberikan.

\section{Desain(Design)}

Tahap ini merupakan tahap penjabaran secara rinci spesifikasi media yang akan dibuat dan menjelaskan langkah-langkah pembuatannya. Spesifikasi yang dijabarkan meliputi materi modul, kerangka modul, dan storyboard. Pembuatan desain berdasarkan dari hasil analisis kebutuhan yang telah dilakukan pada tahap konsep. 
Analisis kebutuhan adalah tahap penting dalam prinsip pengembangan modul yang menjadi dasar desain pengembangan modul. Sehingga desain modul dibuat sesuai dengan kebutuhan calon pengguna yakni siswa. Berikut adalah tahap desain perancangan media pembelajaran modul nama-simbol kelistrikan dan wiring diagram berbasis KKNI menggunkan bantuan $e$ publication:

\section{a. Menetukan referensi}

Berdasarkan hasil analisis materi telah diketahui kompetensi dasar yang akan dimasukkan ke dalam modul yakni kompetensi dasar menerapkan dan menggunakan nama-simbol kelistrikan dan wiring diagram. Referensi yang digunakan diambil dari modul pegangan yang digunakan oleh guru pengampu mata pelajaran kelistrikan otomotif yaitu new step dari TOYOTA.

\section{b. Kerangka modul}

Dalam pengembangan modul ini terdapat bagian teks dan video. Kerangka modul memiliki 3 bagian utama yakni pendahuluan, inti, dan penutup. Berikut kerangka modul kelistrikan otomotif berbasis KKNI menggunkan bantuan e-publication: Kata pengantar Pendahuluan

a) Latar belakang

b) Prasyarat

c) Petunjuk penggunaan

d) Tujuan akhir

Bagian Inti a) Tujuan pembelajaran

b) Uraian materi

Penutup

a) Soal latihan

b) Daftar pustaka

c. Software

Pengembangan media pembelajaran modul kelistrikan otomotif berbasis KKNI menggunkan bantuan e-publication membutuhkan beberapa software. Beberapa software yang digunakan antara lain :

1) Sigil

Sigil adalah aplikasi yang digunakan untuk membuat dan mengedit modul kelistrikan otomotif berbasis KKNI. File output yang dihasilkan berupa file berekstensi *.epub.

2) Adobe Premiere Pro CC 2017 Adobe Premiere Pro CC 2017 merupakan software yang digunakan untuk membuat dan mengedit video yang disisipkan di modul kelistrikan otomotif berbasis KKNI. File output yang dihasilkan berupa file berekstensi *.prproj kemudian setelah dilakukan proses rendering file output yang dihasilkan menjadi berekstensi *.mp4.

3) Microsoft Word

Microsoft word adalah software yang digunakanuntuk membuat dan menyusun materi 
modul awal sebelum dilakukan

proses editing dengan

menggunakan sigil. File

disimpan dalam ekstensi * ${ }^{*}$ html

untuk dapat dibuka pada

aplikasi sigil.

4) Paint

Software ini digunakan untuk

melakukan editing gambar

sehingga dihasilkan gambar

dengan ekstensi *.jpg.

5) Gitden Reader

Gitden reader digunakan untuk membuka file $e$ publication modul kelistrikan otomotif berbasis KKNI yang berekstensi *.epub. Aplikasi ini dapat diperoleh dengan mengunduh dari play store yang terdapat di hp android.

\section{d. Storyboard}

Selain berupa teks, modul kelistrikan otomotif berbasis KKNI menggunkan bantuan e-publication juga dilengkapi dengan video pembelajaran.

Tabel 1 Storyboard modul kelistrikan otomotif berbasis KKNI menggunkan bantuan e-publication

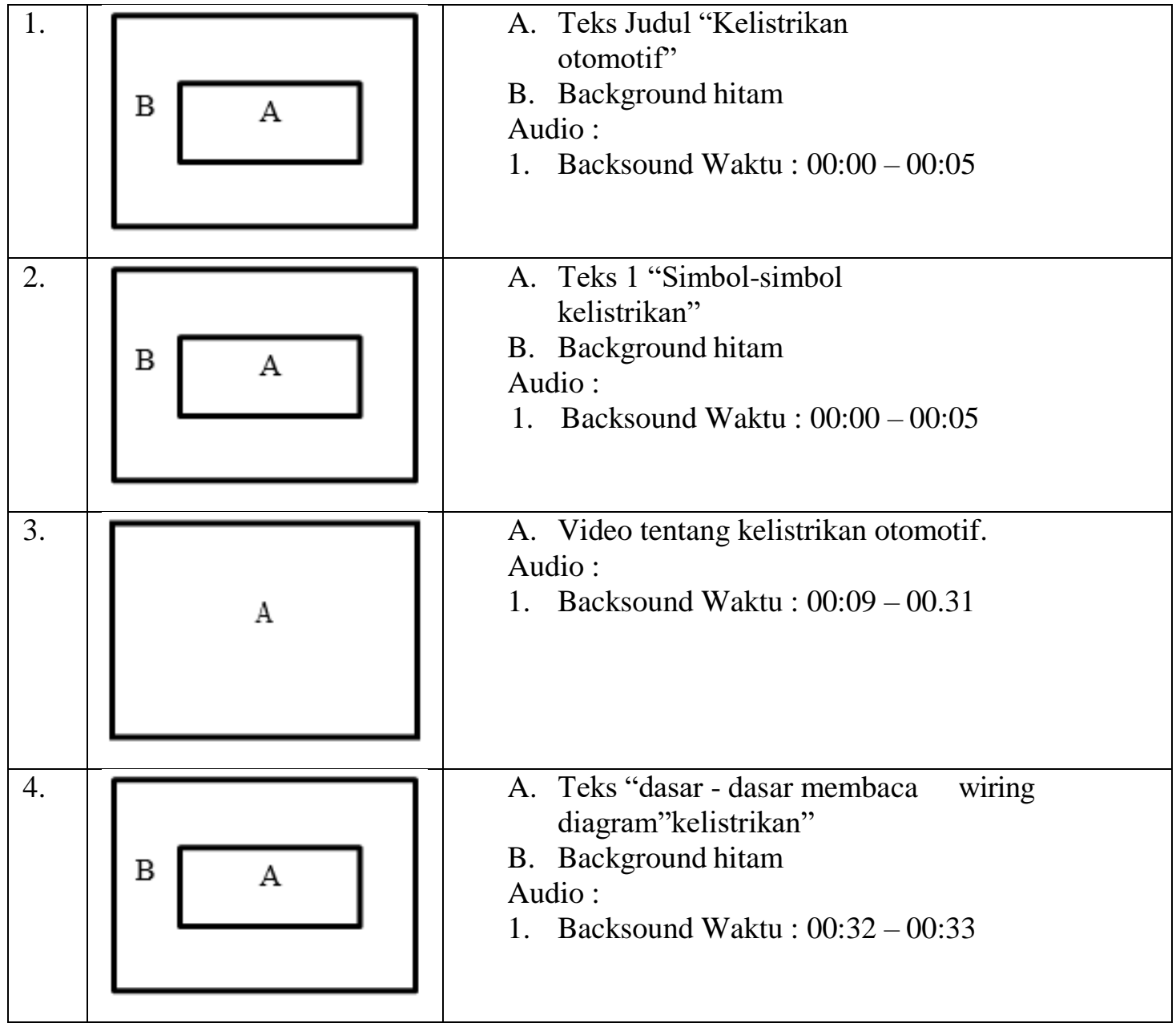




\begin{tabular}{|c|c|c|}
\hline 5. & A & $\begin{array}{l}\text { A. Video wiring diagram } \\
\text { Audio : } \\
\text { 1. Backsound Waktu : 00:34-00:44 }\end{array}$ \\
\hline 6. & B & $\begin{array}{l}\text { A. Teks "Soal penjelasan" } \\
\text { B. Background hitam } \\
\text { Audio : } \\
\text { 1. Backsound } \\
\text { 2. Prolog penjelas Waktu : 00:45-00:47 }\end{array}$ \\
\hline 7. & B & $\begin{array}{l}\text { A. Teks "SEKIAN" } \\
\text { B. Background hitam } \\
\text { Audio : } \\
\text { 1. Backsound Waktu : 01:44-02:33 }\end{array}$ \\
\hline
\end{tabular}

3. Bagian 3: Diskusi hasil modul dan revisi modul.

Modul kelistrikan otomotif berbasis KKNI menggunkan bantuan $e$ publication adalah media pembelajaran berupa modul yang dibuka dengan menggunakan aplikasi yang terdapat pada smartphone. Pengujian sistem dilakukan untuk mengetahui spesifikasi smartphone minimal untuk menggunakan fungsi dasar $e$ publication. Spesifikasi yang ditentukan pada pengujian sistem ini adalah kapasitas RAM (Random Aacces Memory) yang dimiliki. RAM merupakan media penyimpan sementara ketika suatu aplikasi sedang dijalankan/digunakan. Pengujian sistem ini menggunakan 3 jenis RAM yang digunakan pada smartphone, yakni kapasitas 512 MB, 1024 MB, dan 1500 MB. Hasil pengujian dapat dijelaskan sebagai berikut :

Tabel 2 Hasil pengujian system

\begin{tabular}{llccc}
\hline \multirow{2}{*}{ No } & Menu pada Aplikasi & \multicolumn{3}{c}{ Spesifikasi RAM Smartphone } \\
\cline { 3 - 5 } & & $512 \mathrm{MB}$ & $1024 \mathrm{MB}$ & $1500 \mathrm{MB}$ \\
\hline 1 & Membuka Aplikasi Gitden Reader & $\sqrt{ }$ & $\sqrt{ }$ & $\sqrt{ }$ \\
\hline 2 & Melakukan Importing File Modul & $\sqrt{ }$ & $\sqrt{ }$ & $\sqrt{ }$ \\
\hline 3 & Membuka modul kelistrikan otomotif & $\sqrt{ }$ & $\sqrt{ }$ & $\sqrt{ }$ \\
\hline 4 & Menggunakan menu Home & $\sqrt{ }$ & $\sqrt{ }$ & $\sqrt{ }$
\end{tabular}




\begin{tabular}{lllll}
\hline 5 & Menggunakan menu daftar isi & $\sqrt{ }$ & $\sqrt{ }$ & $\sqrt{ }$ \\
\hline 6 & Menggunakan menu voice smart & $\sqrt{ }$ & $\sqrt{ }$ & $\sqrt{ }$ \\
\hline 7 & $\begin{array}{l}\text { Menggunakan menu pengaturan } \\
\text { halaman, ukuran huruf, dan } \\
\text { background modul. }\end{array}$ & $\sqrt{ }$ & $\sqrt{ }$ & $\sqrt{ }$ \\
\hline 8 & Menggunakan menu search & & & $\sqrt{ }$ \\
\hline 9 & Menggunaka penanda halaman & $\sqrt{ }$ & $\sqrt{ }$ & $\sqrt{ }$ \\
\hline 10 & Menggunakan pengaturan kecerahan & $\sqrt{ }$ & $\sqrt{ }$ & $\sqrt{ }$ \\
\hline 11 & Menggunakan scrool bar & $\sqrt{ }$ & $\sqrt{ }$ & $\sqrt{ }$ \\
\hline 12 & Menggunakan auto rotate & $\sqrt{ }$ & $\sqrt{ }$ & \\
\hline
\end{tabular}

Keterangan :

$\sqrt{ }=$ Fungsi berjalan

$\mathrm{X}=$ Fungsi berhenti

Berdasarkan hasil pengujian yang ditunjukkan pada tabel 4.4 diketahui bahwa fungsi dasar pada e-publication modul kelistrikan otomotif berbasis KKNI secara umum dapat berjalan sebagaimana fungsinya ditandai dengan tidak adanya kegagalan fungsi pada 12 poin pengujian yang dilakukan. Dimulai dari proses membuka aplikasi gitden reader hingga penggunaan menu yang tersedia pada aplikasi tersebut semua fungsi dapat digunakan. Ketiga jenis RAM smartphone yang digunakan untuk pengujian, semua fungsi dapat berjalan/digunakan. Tetapi pada smartphone dengan kapasitas RAM 512 MB respon dari perangkat terhadap perintah menu yg digunakan cukup lambat sehingga dirasa kurang nyaman saat digunakan dibandingkan dengan perangkat yg memiliki kapasitas 1024 MB dan 1500 MB. 


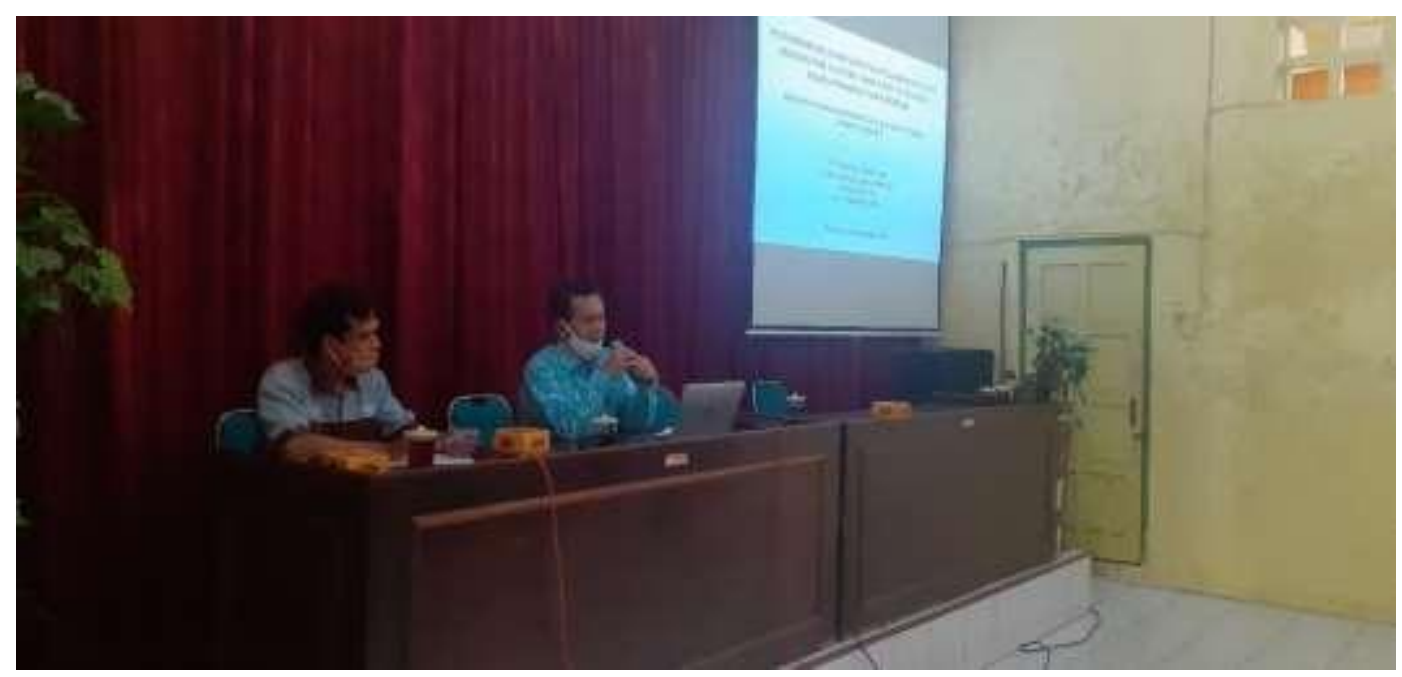

a.

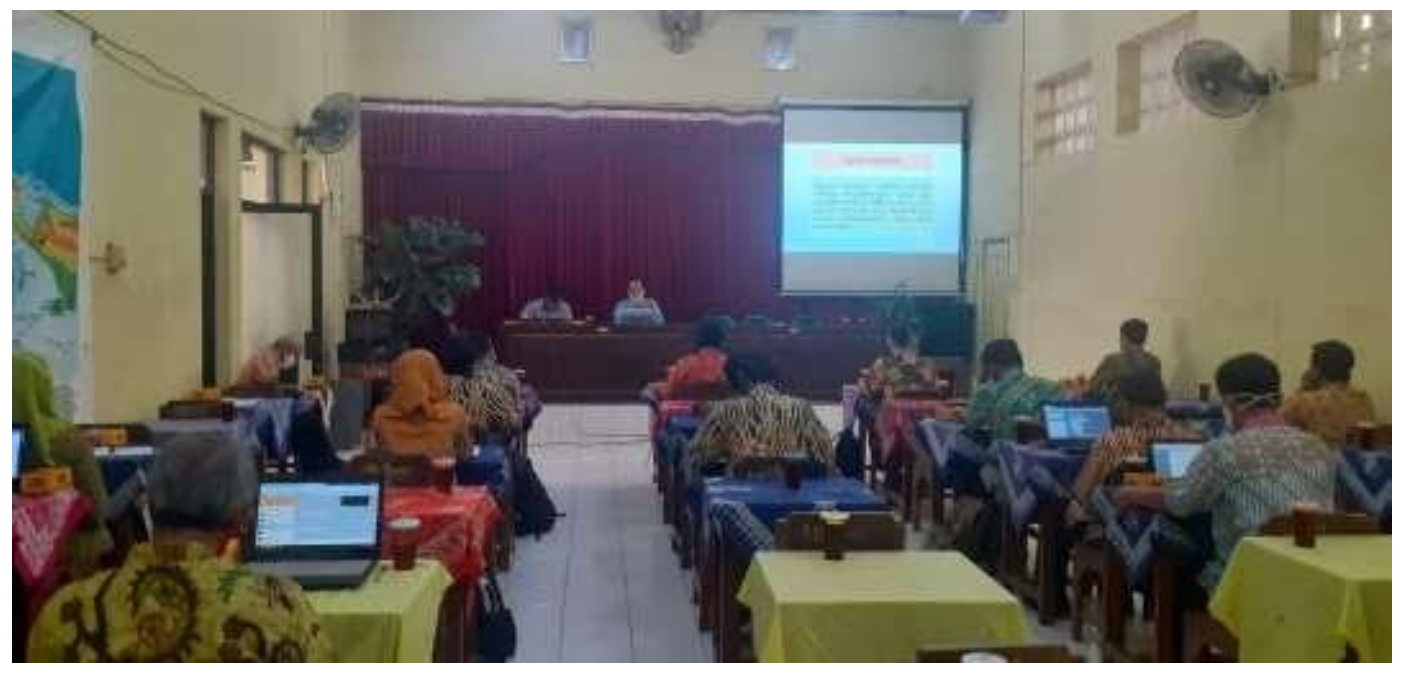

b.

Gambar 2 (a) Diskusi hasil modul; (b) Revisi modul.

\section{KESIMPULAN}

Produk dari kegiatan pengabdian ini adalah terlatihnya guru-guru SMK pengampu mata pelajaran produktif di Kota Surakarta dalam menyusun dan mengembangkan modul pembelajaran mata pelajaran produktif teknik kendaraan ringan otomotif yang selaras dengan KKNI level 2 dan kompetensi teknisi otomotif di industri. Modul disusun dengan bantuan epublication. Dampak yang diharapkan dari kegiatan ini adalah tersusunnya modul pembelajaran oleh para guru, yang selanjutnya dapat digunakan dalam proses pembelajarannya. Dengan demikian proses pembelajaran dapat meningkat kualitasnya, sehingga kompetensi siswa akan meningkat. Contoh yang dikembangkan pada pelatihan adalan Modul kelistrikan otomotif berbasis KKNI menggunkan bantuan e-publication dapat digunakan pada smartphone dengan kapasitas RAM 512 MB, 1024 MB dan 1500 MB ditandai dengan semua fungsi dasar $e$ publication dapat berjalan. Tetapi untuk kapasitas RAM 512 memiliki respon yang lebih lambat dibandingkan dengan kapasitas RAM yang lain. 


\section{DAFTAR PUSTAKA}

Estriyanto Y, Kersten S, Pardjono, Sofyan H. 2017 The Missing Productive Vocational High School Teacher Competency Standard in the Indonesian Education System. J. Tech. Educ. Train 9 26-44

Kapasir C, Van Tien M, Lim S, Phuong P, Huy P, Schnarr A 2019 Linking Vocational Training with the Enterprises - Asian Perspectives InWEnt - Internationale

Weiterbildung und Entwicklung gGmbH Bonn, Germany

Prosser CA, Ouigley TA 1950 Vocational Education in a Democracy. Chicago: American Technical Society

Saputro H, Widiastuti I, Harjanto B 2018 Production-Based Education Model for Improving Technical and Vocational Teachers Ability IOP Conf. Series: Materials Science and Engineering 306, 012052 Toyota Astra Motor. 2016. Buku Manual Toyota Avanza. Jakarta

Undang-undang N0. 20 Tahun 2003 tentang Sistem Pendidikan Nasional Republik Indonesia.

Wibowo AE, Munadi S 2019 Machining industry's contribution level in vocational high school revitalization. IOP Conf. Ser. Mater. Sci. Eng. 535:0-7. 